\title{
3-D WATER QUALITY SIMULATIONS IN MORNOS RESERVOIR
}

\author{
I.A. PAPADIMITRAKIS \\ S. KARALIS
}

\author{
National Technical University of Athens \\ School of Civil Engineering \\ Water Resources \& Environmental Engineering Div \\ 5 Heroon Polytechniou St., Zografos 15780, Athens, Greece
}

Received: 13/10/08

Accepted: 05/01/09 *to whom all correspondence should be addressed: e-mail: ypapadim@central.ntua

\begin{abstract}
Simulations were performed of the 3-D hydrodynamic circulation and of the associated water quality behavior in Mornos Reservoir, under real environmental conditions, during the period 2003-2005. The water quality simulations, guided by observations taken at the contributing tributaries and at the surface of the Reservoir, generated in-depth profiles of $\mathrm{pH}, \mathrm{DO}, \mathrm{NO}_{3}, \mathrm{NH}_{4}, \mathrm{TN}, \mathrm{TKN}, \mathrm{PO}_{4}, \mathrm{TP}, \mathrm{TOC}$ and of $\mathrm{Chl}-\mathrm{a}$, along with surface and indepth horizontal distributions of these quantities, giving an overview of the variation of the Reservoir's water quality. Comparison of plots of the simulated quantities with field data indicates that the Reservoir remains indeed oligotrophic; it also shows the potential of the tools used, and the need for acquiring more systematic "in situ" observations by EYDAP (the water authority company responsible for managing Mornos Reservoir).
\end{abstract}

KEYWORDS: 3D Models, Reservoirs, Hydrodynamic \& Water Quality simulation.

\section{INTRODUCTION}

The importance of monitoring the quality of water in Mornos, a Reservoir which supplies potable water to the greater metropolitan area of Athens and supports, on the average, 4.5 million people daily, is more than obvious, even though this water is subject to treatment at the various treatment facilities located at the outskirts of Athens city. Evaluation of the quality of water in such an impoundment may be achieved by simulating the hydrodynamics and the various biogeochemical processes regulating the quality of water in it. Sophisticated physical and water quality-ecological models, describing in great detail the Reservoir hydrodynamics and biogeochemistry, not only contribute to the better understanding of all governing processes but also help in adopting measures to protect such bodies of natural waters from deterioration that maybe caused by land use malpractices exercised by humans on neighboring areas, etc.

Mornos Reservoir is located near Lidoriki, a small town of Fokida in the western part of central Greece (Figure 1a). The Reservoir is a deep water enclosure with a maximum depth exceeding $100 \mathrm{~m}$ and an average depth of $52 \mathrm{~m}$, or more. It has an area extent of $20 \mathrm{~km}^{2}$ and a volume of $760 \times 10^{6} \mathrm{~m}^{3}$ of water. It consists of two sub-basins communicating through a relatively narrow $(<200 \mathrm{~m})$ and deep $(\sim 75 \mathrm{~m})$ canal-like stretch. The subbasin of Mornos dam (at the western side) has all features that a lacustrine lake exhibits, whereas the sub-basin from which water is withdrawn (at the eastern side) looks like a riverine lake. Each sub-basin consists of two branches; thus the Reservoir has a butterfly like shape. The maximum length and width among the four branches of the Reservoir are 10 and $2.5 \mathrm{~km}$, respectively. All of the above figures represent average reservoir characteristic dimensions during the simulation period 2003-2005. Mornos river and three smaller creaks (Kokkinos, Avoros, and Harmenorama) discharge into the Reservoir, whereas a water outlet (at the elevation of $384 \mathrm{~m}$ ), near Lidoriki, outflows into the aqueduct system that supplies water to the greater Athens metropolitan area. Another sink, 
located also near Lidoriki, abducts water locally through the Reservoir's bottom at a rate depending on the water elevation in the Reservoir.

The Reservoir's bathymetry (Figure $1 \mathrm{~b}$ ) was obtained by digitizing maps provided by the Greek Army Geographical Service. A 200×200x1 m grid was created first; then, using the generated grid and interpolation techniques, a new stage-volume curve was developed from the available stage measurements and the amount of water withdrawn, for estimating the inflows from rivers into the Reservoir.

This paper is based on the postgraduate Thesis work of the second author (Karalis, 2007), conducted under the guidance and supervision of the first author. The structure of the paper has as follows: section 2 presents briefly the simulation models used, section 3 describes the external forcing and the water quality data used to guide the simulations, section 4 presents some simulation results along with a short discussion, and section 5 contains pertinent conclusions.
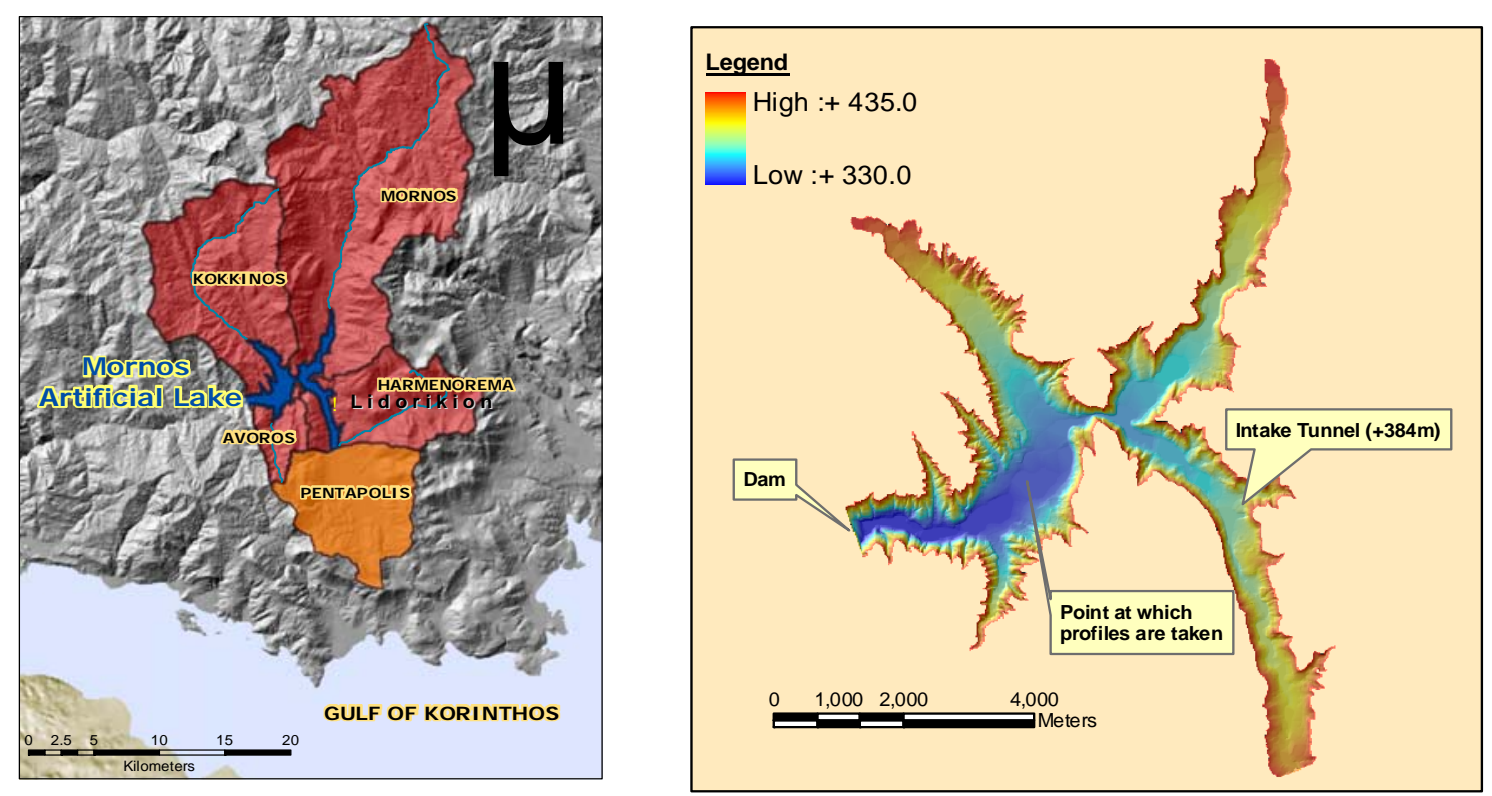

Figures $1(a, b)$. Reservoir's map and bathymetry

\section{MODEL CONSIDERATIONS}

Due to its irregular shoreline and complex surface shape and bathymetry, it was felt that Mornos Reservoir cannot be adequately simulated by 1-D or 2-D mathematical models. An advanced 3-D hydrodynamic model, coupled with an also advanced water quality and aquatic ecosystem model, aught to be chosen to simulate the 3-D transport and interactions of flow physics, biology and chemistry in the Reservoir. ELCOM (Estuary Lake and Coastal Ocean Model) and CAEDYM (Computational Aquatic Ecosystem DYnamics Model) appears to be a suitable pair of models that meets the above requirements and has been used in this study. ELCOM is designed for numerical simulations of hydrodynamics and thermodynamics of inland and coastal waters. This hydrodynamic code links seamlessly with the CAEDYM model. The combination of the two codes provides a threedimensional simulation capability for examination of detailed changes of water quality in any lake-Reservoir.

ELCOM simulates Reservoir hydrodynamics by considering the various physical processes acting in the Reservoir, whereas CAEDYM simulates the basic geochemical and biological processes affecting the quality of water in the Reservoir. Both models have been developed by the Center for Water Research of the University of Western Australia (Hodges and Dallimore, 2001; Hipsey et al., 2003). CAEDYM is the water quality 'module' of the combined model that uses ELCOM as its hydrodynamic 'driver'. The outcome of the hydrodynamic simulation (via ELCOM) is a detailed characterization of water 
movement and mixing in the Reservoir, coupled with a description of its thermal stratification. ELCOM solves the Reynolds averaged equations (with or without the Coriolis term), using Boussinesq approximation and neglecting the non-hydrostatic pressure terms. In the horizontal direction, turbulence is treated using a constant eddy viscosity coefficient, whereas in the vertical direction an energy model is used for mixing sequential layers. Density is calculated from salinity and temperature through an algebraic equation, while the salinity and temperature are calculated through differential equations of diffusive transport. The coupled models/modules provide a powerful tool for studying the spatial and temporal relationships between physical, biological and chemical processes in Mornos Reservoir. The mathematical formalism of physical and biochemical processes, and the parameters and coefficients used by ELCOM-CAEDYM, have been described by Karalis, 2007). Relevant references, with respect to CAEDYM, may also be found in Chioni (2005) and in Papadimitrakis and Chioni (2006), whereas interesting applications of these two models can be found in Hannoun et al. (2006), Leon et al. (2005) and Feaver et al. (2002). More specific applications of ELCOM, related to the behavior of internal waves in a stratified lake, can be found in Hodges et al. (2000).

It is worth noting that ELCOM usually requires minor calibration adjustments, since the variation of most of its parameters is well defined by the conservation equations of mass, momentum and energy containing few adjustable coefficients. CAEDYM' s calibration, however, is more complicated, as a result of the intricate biochemical processes and the large number of coefficients associated with the model inputs. CAEDYM requires a minimum configuration for simulating water quality parameters, besides $\mathrm{pH}$ and $\mathrm{DO}$. It requires POCL (particulate organic carbon labile) and DOCL (dissolved organic carbon labile), PONL (particulate organic nitrogen labile) and DONL (dissolved organic nitrogen labile), $\mathrm{NO}_{3}$ and $\mathrm{NH}_{4}, \mathrm{POPL}$ (particulate organic phosphorus labile), DOPL (dissolved organic phosphorus labile) and $\mathrm{PO}_{4}$. The assumptions made, based on available data, for estimating these input variables are that: $\mathrm{POC}=\mathrm{DOC}=\mathrm{TOC} / 2, \mathrm{NO}_{3}$ includes both $\mathrm{NO}_{3}$ and $\mathrm{NO}_{2}$ concentrations, $\mathrm{DON}=\mathrm{PON}=\left(\mathrm{TKN}-\mathrm{NH}_{4}\right) / 2$, and for phosphorus: $\mathrm{PO}_{4}=$ $0.7 \mathrm{TP}$ and $\mathrm{DOP}=\mathrm{POP}=0.15 \mathrm{TP} ; \mathrm{TKN}$ represents the total Kjental nitrogen.

\section{FIELD DATA}

Simulating, with the aid of ELCOM, the Reservoir hydrodynamics requires detailed information on the external forcing (i.e., meteorological conditions, inflows-outflows, rain, water losses, heat exchange through the air-water interface, and the fluxes of various substances entering the Reservoir through the contributing tributaries), over the simulation period (2003-2005). Meteorological data, such as: air temperature, relative humidity, wind speed and direction, cloud cover and shortwave (solar) radiation, were provided by an automated station that the water authority, responsible for the operation of the Reservoir (i.e., EYDAP), had installed at the water intake tunnel in 2002; rainfall data were obtained from a meteorological station at the nearby town of Lidoriki. Mass balance data for Mornos, along with measurements of several water quality parameters taken at the entrances of the various tributaries into the Reservoir, and concentrations of DO, TOC, $\mathrm{NO}_{3}, \mathrm{NH}_{4}, \mathrm{TN}, \mathrm{TKN}, \mathrm{PO}_{4}, \mathrm{TP}, \mathrm{TChl}-\mathrm{a}$ measured at seven locations on the surface of the Reservoir, were also provided by EYDAP.

The total daily drainage, from the surrounding watersheds, was partitioned into the four riverscreaks discharging into the Reservoir, according to the fractional drainage contribution of each watershed to these tributaries. Thus, it was found that Mornos river contributes $53 \%$, Kokkinos 27\% (plus any inflow from Evinos river), Harmenorema 16\% and Avoros $4 \%$ of the total daily discharges into the Reservoir. The temperature of these inflows was estimated from the corresponding air temperature, averaged over the 4 preceding days. Furthermore, in order to guide the water quality simulation first and then compare the generated results with available observations during the simulation period, the 'in situ' data taken by EYDAP on the Reservoir's surface, at the entering intersections of the contributing tributaries, were used. Figure 2 shows the variation of meteorological forcing obtained from the automated station, during the simulation period. The upper two graphs show averaged weekly values of solar radiation (in $\mathrm{W} \mathrm{m}^{-2}$ ) and of air temperature (in ${ }^{\circ} \mathrm{C}$ ), whereas the lower graph shows weekly 
maximum values of wind speed (in $\mathrm{m} \mathrm{s}^{-1}$ ), over the same period.
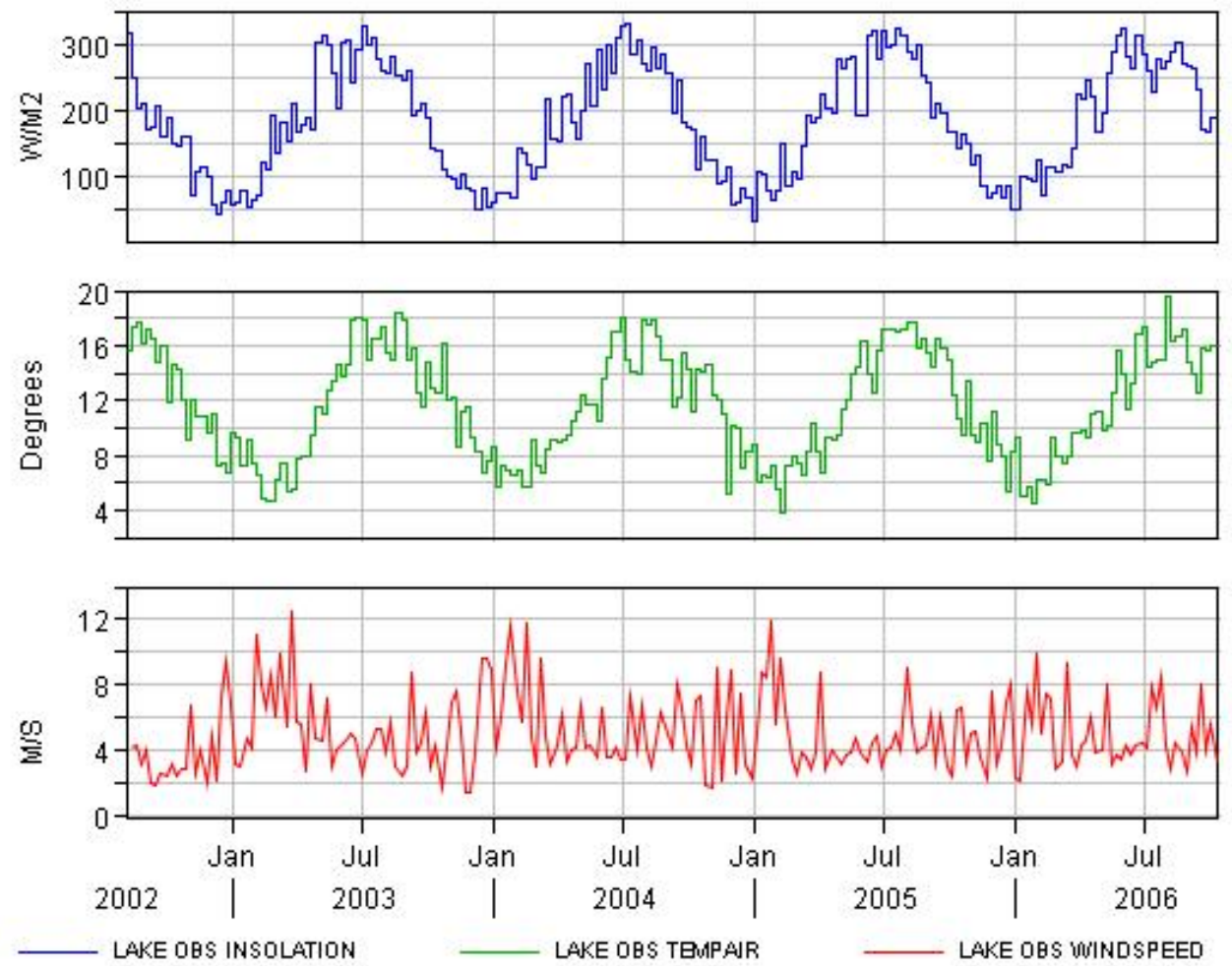

Figure 2. Averaged weekly solar radiation $\left(\mathrm{W} \mathrm{m}^{-2}\right)$, Air temperature $\left({ }^{\circ} \mathrm{C}\right)$, Weekly max of wind speed $\left(\mathrm{m} \mathrm{s}^{-1}\right)$

Mornos Reservoir is surrounded by a mountainous terrain whose peaks reach far above the maximum water elevation of $435 \mathrm{~m}$ (Giona reaches 2034, Vardousia 2363 and Katsilieris $1088 \mathrm{~m}$ ). Mornos is also an area rich in precipitation (with an average precipitation of $940 \mathrm{~mm}$ year $^{-1}$ ). From the available meteorological data, it appears that the regional climate has a short summer and a long, cold and windy winter. Wind is stronger during February-March and throughout spring, but remains mild during October-November.

\section{SIMULATION RESULTS AND DISCUSSION}

Simulation results are available at several points specified by the user. For brevity, indepth profiles of the physical and of the water quality parameters simulated, were extracted from- and displayed at only a characteristic point considered to be representative of the whole Reservoir (Figure 1b).

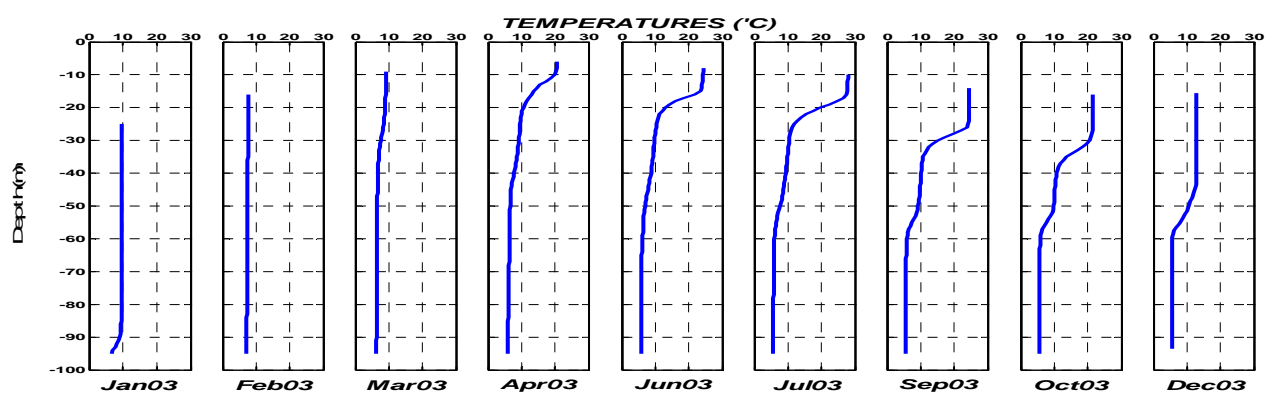

Figure 3. Temperature profiles during 2003

\subsection{Temperature simulation}

The stratification-destratification process is exhibited very clearly in Figure 3 , showing the in-depth seasonal variations of temperature, at the selected location, during 2003. As seen, the Reservoir exhibits a structure with two thermoclines, whenever the surface wa- 
ter elevation is sufficiently high during the months of September and October. It is noted that, in the following two months of November-December, the upper thermocline sinks and progressively disappears. The lower thermocline sinks during January and, subsequently, disappears in February, rendering Reservoir's water thermally homogeneous at that time. February and March are the months of (thermal) inversion, whereas April marks the beginning of stratification with the formation of a weak thermocline (of about 2 ${ }^{\circ} \mathrm{C}$ ) at the depth of $8 \mathrm{~m}$ below the Reservoir's surface. Stratification becomes well formed in May and peaks during the following summer. Consistent with the above picture is the evolution of the diurnal surface mixed layer (see Karalis, 2007) which exhibits the indepth temperature variation during distinct days, throughout the simulation period (20032005).

\subsection{Water quality parameters}

A picture of the Reservoir behavior and status can be obtained from the profiles of simulated water quality parameters. Figure 4 shows in-depth profiles of DO, whereas Figure 5 shows in-depth distributions of $\mathrm{NO}_{3}$ in the two sub-basins. Figure 6 shows profiles of the total Chl-a (TChl-a), and Figures 7(a,b,c,d) show horizontal distributions of the same variable at the surface of the Reservoir in the middle of four characteristic months of 2003 (from late in the spring to early in the fall). Figures $8(a, b)$ present average monthly variations of simulated DO and TN concentration results, at the Reservoir's surface, along with their counterpart field values (provided again by EYDAP).
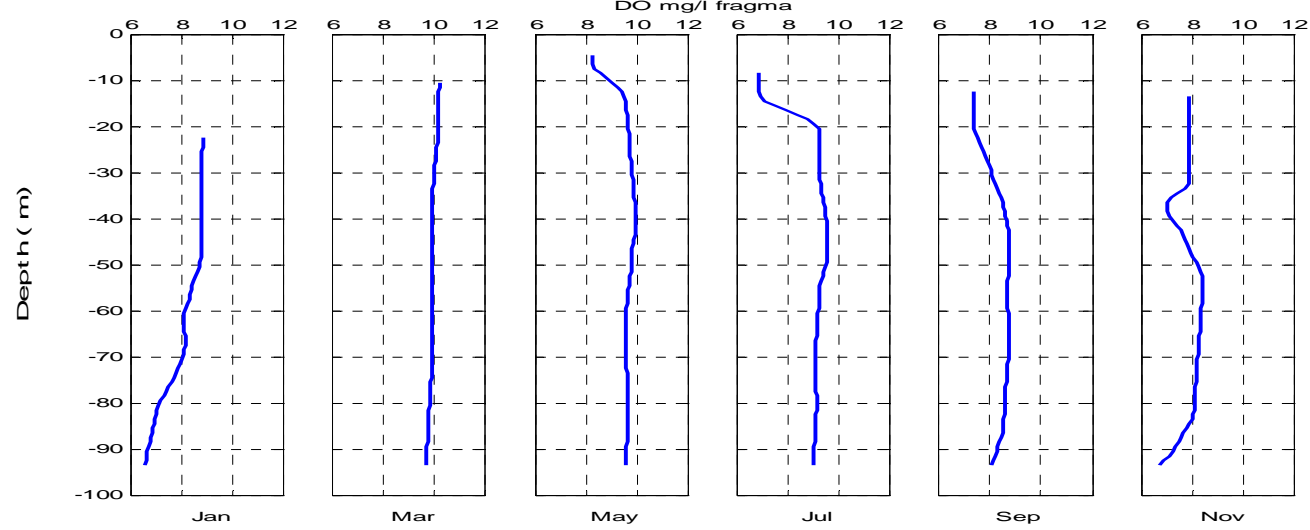

Figure 4. Profiles of DO $\left(\mathrm{mg} \mathrm{l}^{-1}\right)$

These results show that Mornos is a well oxygenated Reservoir. In the summer, due to the increased surface water temperature, a reduction in DO concentrations at the Reservoir's surface is observed, but as the summer progresses oxygen becomes more abundant (and particularly at greater depths) establishing an orthograde DO profile. This picture is consistent with the behavior of oligotrophic lakes at high altitudes, where the quantity of organic matter produced during the summer, and sinking to the hypolimnion, is not sufficient to reduce the available oxygen content of deeper waters. With regard to nutrients, time series measurements of Nitrogen $(\mathrm{N})$ concentrations in the Reservoir, provided by EYDAP, indicate increased values $\left(\sim 1 \mathrm{mg} \mathrm{l}^{-1}\right)$ of the latter during the first four months of the year, which are also the months of high inflows. At that time, oxidized species of $\mathrm{N}$ are dominant in relation to organic N. For the rest of the time, Nitrogen concentrations appear very low $\left(<0.2 \mathrm{mg} \mathrm{l}^{-1}\right)$ and are essentially of organic origin. The same pattern, somehow exaggerated, applies to the measurements of $\mathrm{N}$ of the inflows.

It also appears (Karalis, 2007) that $\mathrm{NO}_{3}$ concentrations remain nearly constant during spring, but diminish in summer across the epilimnion, possibly due to the lowered DO concentrations found in that region. The increase found in the calculated $\mathrm{NH}_{4}$ values, at the Reservoir's bottom, is likely owed to the decomposition of the organic material there. Phosphorus concentrations are traced rarely, and when they are (5 times out of 36 ) they appear to be very low $\left(4 \mathrm{Mg} \mathrm{I}^{-1}\right)$. In 2003, inflows indicated an average of about $6 \mu \mathrm{g} \mathrm{I}^{-1}$ of TP (during the month of April). It, therefore, appears that eutrophication is controlled by the lack of Phosphorous (taking into account the lack of information related to sediments, and to the sediment-water column fluxes). 

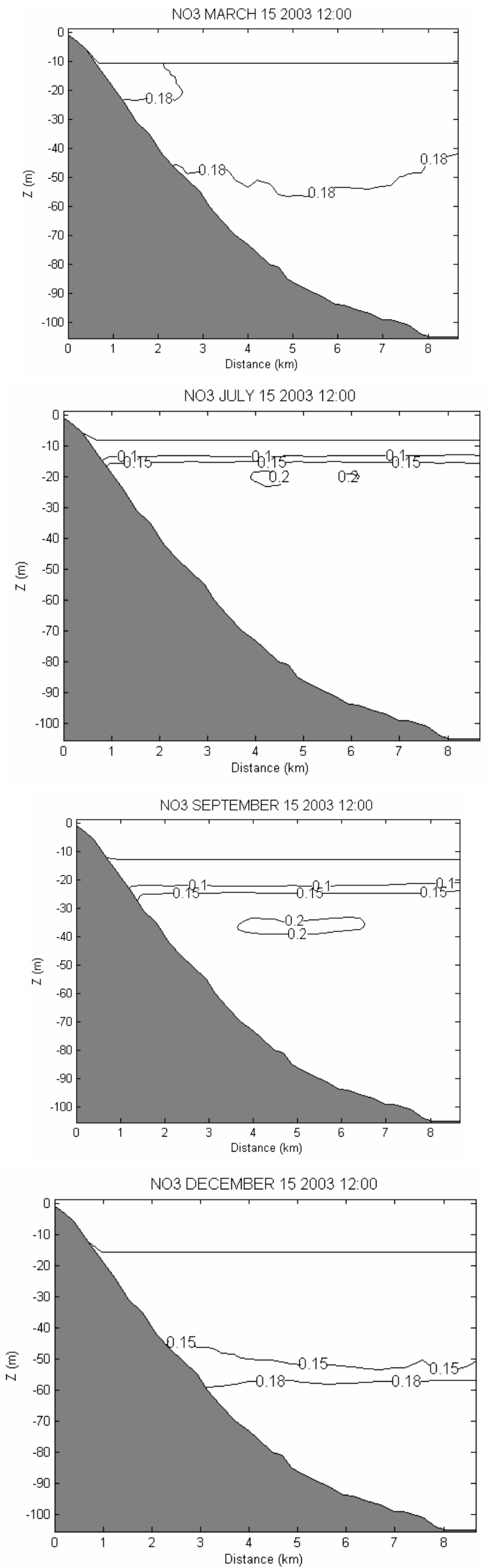
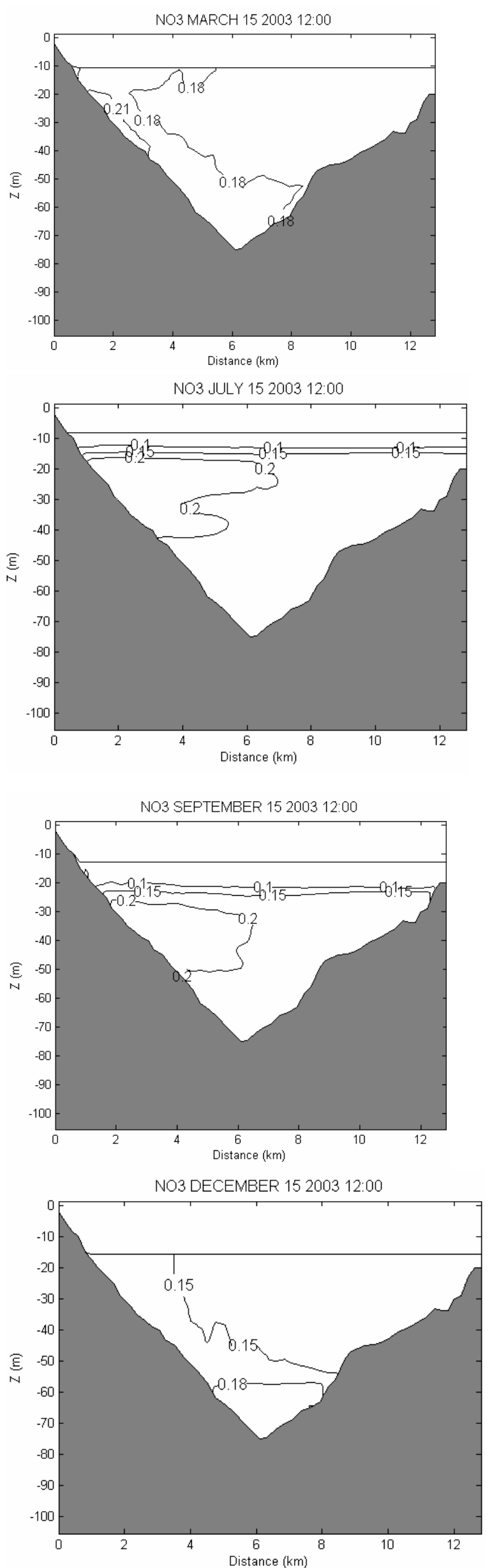

Figure 5. Yearly in-depth distributions of $\mathrm{NO}_{3}\left(\mathrm{mg} \mathrm{l}^{-1}\right)$ in the two sub-basins 

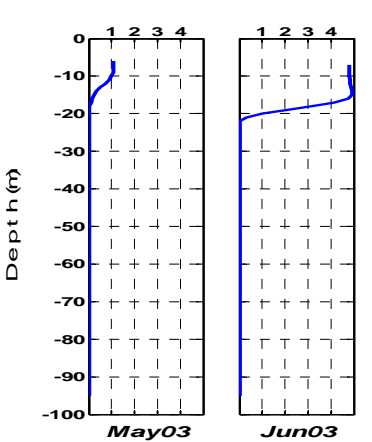
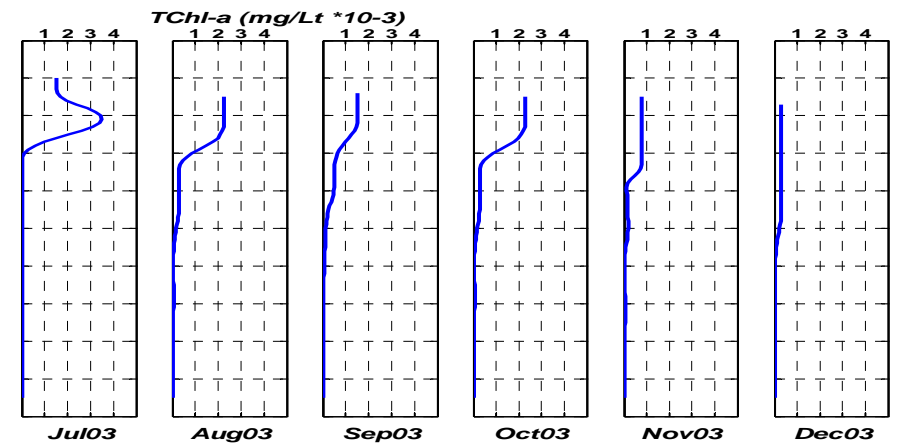

Figure 6. Profiles of total Chl-a $\left(\mu \mathrm{g} \mathrm{I}^{-1}\right)$
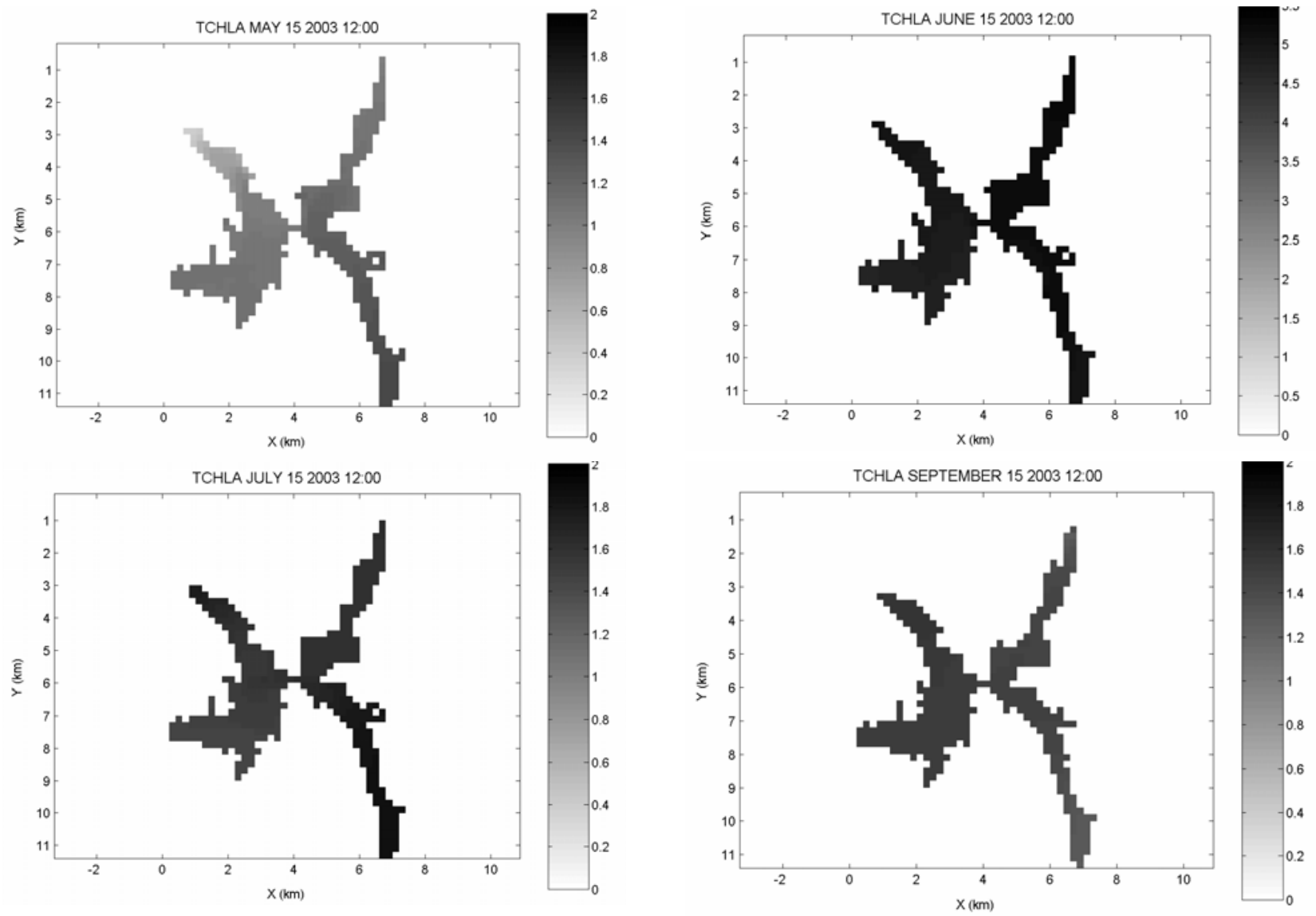

Figures $7(a, b, c, d)$. TChl-a $\left(\mu \mathrm{gl}^{-1}\right)$ spatial distribution at the Reservoir's surface in the middle of May, June, July and September of 2003

The TChl-a simulation results (in Figures 7) show a maximum of $5 \mu \mathrm{g} \mathrm{I}^{-1}$, during June 2003. This concentration is reduced to values lower than $2 \mu \mathrm{m} \mathrm{I}^{-1}$, during the subsequent months. Finally, photosynthetic activity appears to cease in November and December. It is noted here that the profiles of TChl-a, in July and August, suggest a euphotic zone of $\sim 10 \mathrm{~m}$ deep which is greater than the mixed layer depth of $\sim 5 \div 7 \mathrm{~m}$. These profiles of TChl-a are characteristic of such cases, where the maximum of chlorophyll productivity occurs within a euphotic zone extending below the turbulent mixed layer. The maximum value of $5 \mathrm{\mu g}^{-1}$, predicted by the combined model, characterizes Reservoirs with an ecological status in-between oligotrophic and mesotrophic. Recent measurements of TChl-a, during 2006-2007, showed a peak of about $1 \mu \mathrm{g} \mathrm{I}^{-1}$ occurring also during the period May-June.

There seems to exist a discrepancy, between the combined model prediction and the TChl-a concentration measurements of the Reservoir's water, indicating CAEDYM's increased sensi- 
tivity with regard to phosphorous concentrations and the related parameters. Yet, since these recent measurements do not cover the simulation period, it is suggested that the TChl-a comparison aught to be seen with caution. Judging from Figures 6 and 7, it also appears that TChl-a concentrations show a 3-D variation. While photosynthetic activity starts during May and June, and mainly on the eastern basin, it looks as being transferred to the western basin of the Reservoir later.

It is also important to realize that since no measurements were available in the water column, our effort in describing the water quality characteristics of Mornos Reservoir is more or less limited to comparing the available measurements with the simulation results at the Reservoir's surface. Figures $8(a, b)$ present average monthly variations of simulated DO and TN concentrations, at the Reservoir's surface, along with their counterpart field values (provided again by EYDAP). There is good agreement among DO concentrations and to a lesser extent among TN concentrations, as the model seems to underestimate the TN peak values.
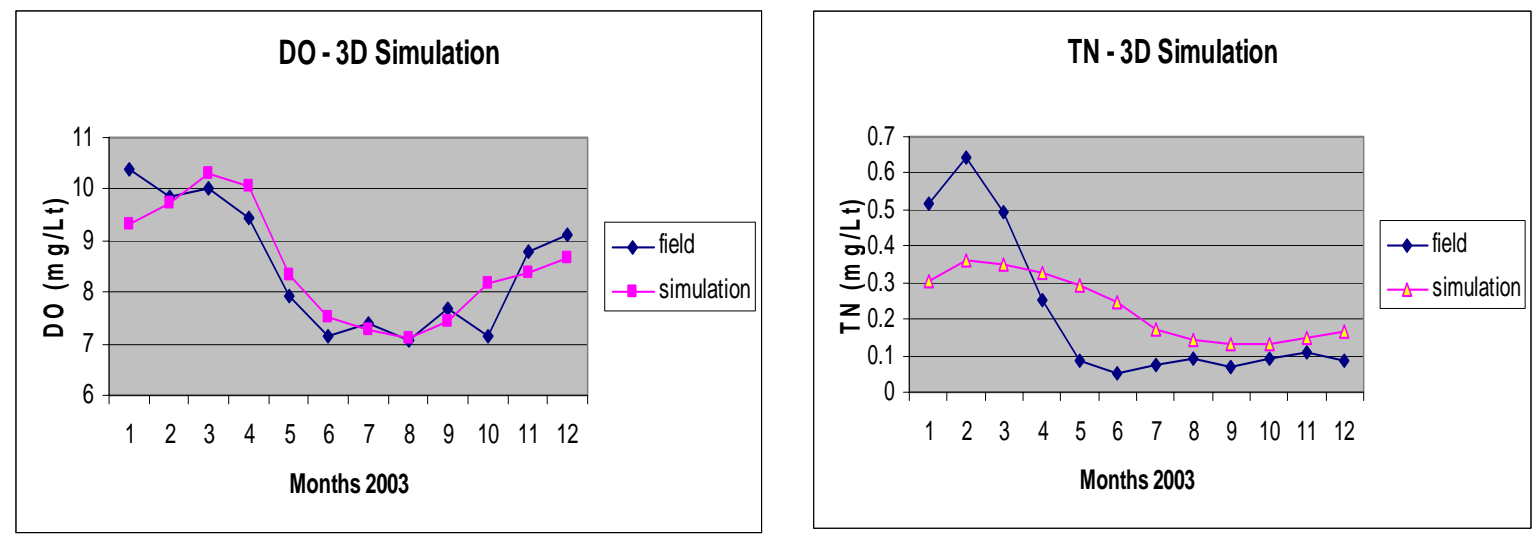

Figures $8(a, b)$. Simulation results vs field measurements for DO and TN

\subsection{Tracer and retention time studies}

Circulation patterns can be also visualized through the use of tracers. These tracers have a dimensionless concentration equal to unity (1) and are assumed to be passive, diluted conservative substances and/or pollutants. Retention time(s) can be estimated by virtue of the fact that the combined model assigns the water of each cell the age of zero, at the start of the simulation period (with regard to any inflowing water afterwards), and increments the age of each cell at each subsequent time step. The water is then transported as any other transportable scalar.
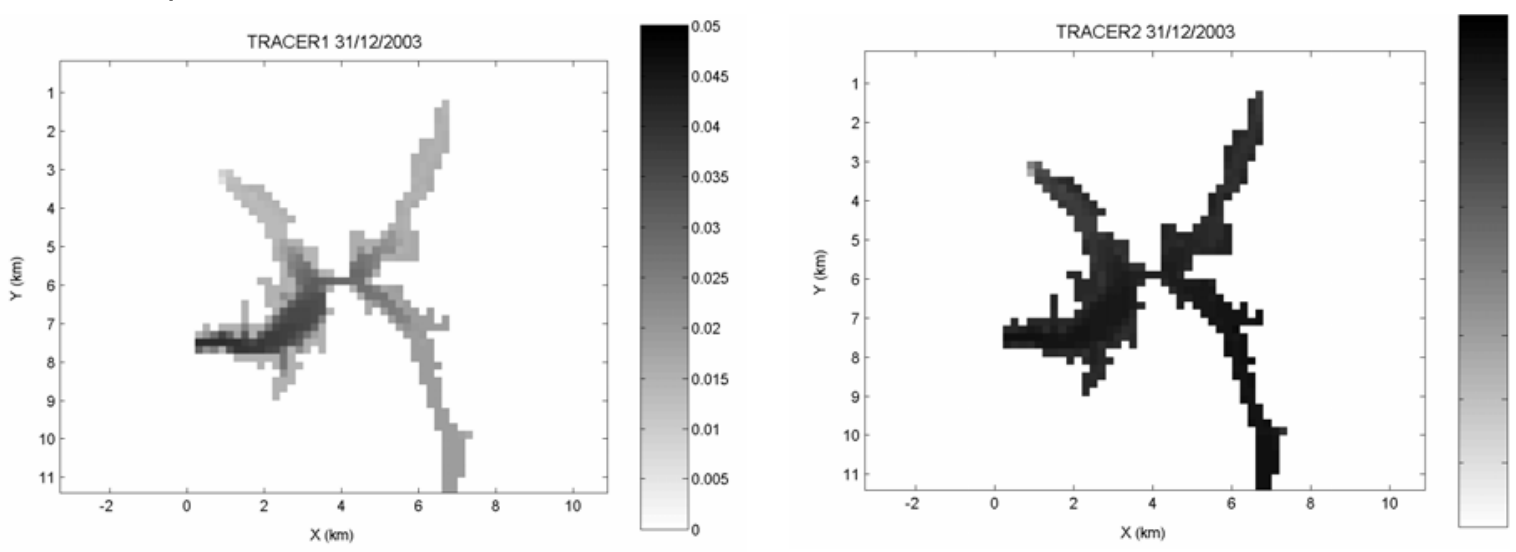

Figures $9(a, b)$. Concentration of the two tracers at the end of the simulation period

Figures $9(a, b)$ show the two tracer concentrations used to simulate the two major inflows into the Reservoir, from Mornos river (tracer 1) and from Kokkinos (tracer 2), 3 years after the beginning of hydrodynamic simulation. It appears that the water from Mornos river 
is mainly directed to- and deposited into the Dam branch of the Reservoir, whereas the water from Kokkinos is (almost) uniformly distributed within the whole Reservoir.

Figure 10 shows vertical profiles of the age of water within the Reservoir (at the same characteristic point) every two months, starting from October of 2004. This Figure indicates the selectivity of water withdrawal (at the elevation of $-55 \mathrm{~m}$ ) and the strong vertical structure of the impounded water. It should be also noted that the only period for replenishing the deep waters (below $-55 \mathrm{~m}$ ) is that of February through April, that is during the months of temperature inversion.

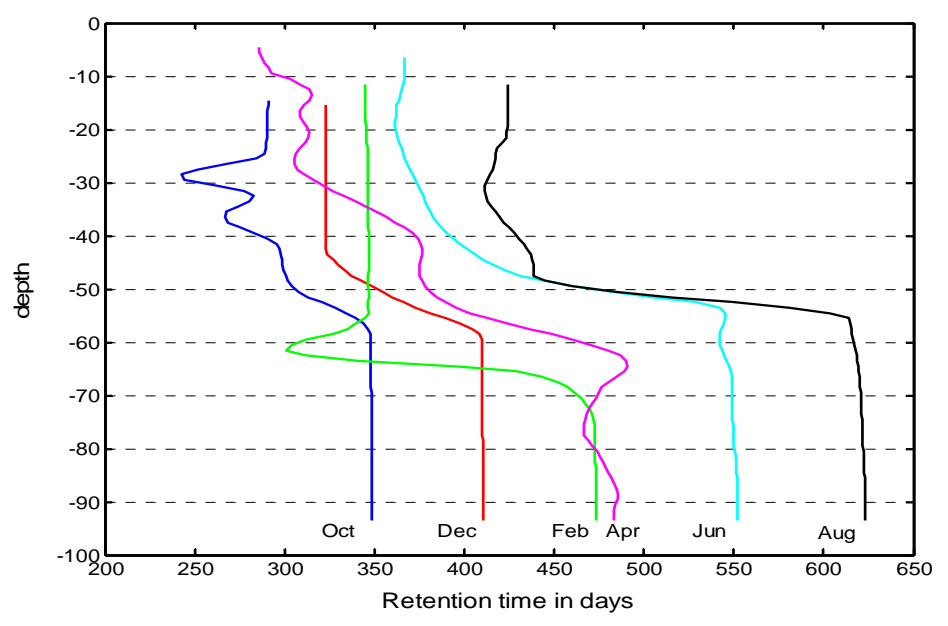

Figure 10. Age profiles of the water at six bimonthly periods

\section{CONCLUDING REMARKS}

The coupling of the two, well advanced models, ELCOM and CAEDYM appears to generate many capabilities in exploring both the physics and the biogeochemistry of artificial lakes-Reservoirs. The performance of these two (coupled) models can be optimized when detailed space-time observations are available and proper attention is paid to the initial conditions that may, to some extent, influence the performance of the models.

Summarizing the findings from this simulation study we may remark that, during the stratification period, colder water sinks down to the lower thermocline; the hypolemnetic water is renewed only in February and in March, leading to large water renewal times in the Reservoir. The water $\mathrm{pH}$ remains nearly constant with depth, except during the summer months when it appears to increase, a fact (possibly) associated with both the photosynthetic activity and the consumption of $\mathrm{CO}_{2}$. Yet, the decomposition of organic material, at the Reservoir's bottom, may cause a decrease in the $\mathrm{pH}$ values with depth. The low simulated concentrations of TChl-a, found at the Reservoir's surface (in Figures 7), and the good agreement among the simulated yearly values and corresponding field results (shown in Figures 10, mainly among DO concentrations and to a lesser extent among TN concentrations) do show the potential of the tools used in this study.

The temperature, DO, nutrient and TChl-a in-depth and horizontal concentration distributions, all indicate that Mornos Reservoir appears to be a warm monomictic lake with an oligotrophic-mesotrophic status. It is also noted here that many of the water quality parameters examined, except the TChl-a, appear to vary little horizontally, as a result of likely strong horizontal diffusion. Thus, it would be interesting to use (in the future) the DYRESM- CAEDYM model combination and compare the corresponding in-depth profiles with the ones produced here. Yet, since CAEDYM is a complicated model, a more thorough calibration (of the latter) utilizing proper water quality (and aquatic ecosystem) data should be in order. Such data must be collected throughout the Reservoir, by EYDAP in a more systematic and continuous fashion, provided that Mornos Reservoir is a very important water enclosure for it supplies with potable water the Athens metropolitan area. 


\section{REFERENCES}

Chioni A. (2005) Multilevel management of water quality in lakes. Application to lake Vegoritis. Diploma Thesis, Nat. Techn. Univ. Athens, Water Res., Hydra. \& Maritime Engrg. Div., Athens, Greece (in Greek).

Feaver S., Lam C., Appt J., Stumpp S. and Molkenthin F., (2002) Implementation of the measurement Programme for lake Constance 2001, International Conference on Hydroscience and Engineering, Warsaw, Poland, 18-21 September 2002.

Hannoun I., List E.J., Kavanagh K.B., Chiang W.-L., Ding L., Preston A., Karafa D. and Rackley I. (2006) Use of ELCOM and CAEDYM for WQ simulation in Boulder basin, Water Environment Foundation (WEFTEC.06), 3943-3970.

Hipsey M.R., Romero J., Antenucci J. and Hamilton D. (2003) Computational Aquatic Ecosystem Dynamics Model (CAEDYM), v2.0 Science Manual. Centre for Water Research, University of Western Australia.

Hodges B.R. and Dallimore C. (2001) Estuary and Lake Computer Model Science Manual Code, Version 1.5.0, Centre for Water Research, University of Western Australia.

Hodges B.R., Imberger J., Saggio A. and Winters K.B. (2000) Modeling basin-scale internal waves in a stratified lake, Limnol. Oceanogr., 45(7), 1603-1620.

Karalis S. (2007) Three-dimensional simulation of water quality in Mornos Reservoir, Post Graduate Thesis, National Technical University of Athens, Science and Technology of Water Resources, Postgraduate Programme, Athens, Greece (in Greek).

Leon L.F., Lam D., Schertzer W. Swayne D. (2005) Lake and climate models linkage: a 3-D hydrodynamic contribution, Advances in Geosciences, 4, 57-62.

Papadimitrakis I. and Chioni A. (2006) Multilevel management of water quality in lakes. Application to lake Vegoritis. In: Protection and Restoration of the Environment VIII, Extended Abstract Document and Proc. CD, E. Gidarakos, N. Nikolaidis, C., Christodoulatos, G. Karatzas, E. Diamantopoulos, D. Mantzavinos, A. Koutsospyros, D. Dermatas, E. Psillaki, E. Paleologos, M. Lazaridis, A. Koungolos and T. Tsoutsos, Eds., (Abstract, pg. 369), article 8 pp. 